\title{
Intelligent Maintenance Prioritization and Optimization Strategies for Thermal Power Plant Boilers
}

\author{
Noor Fazreen Ahmad Fuzi, Firas Basim Ismail
}

\begin{abstract}
Steam boiler also known as steam generator is an integral component in thermal power plants requiring effective maintenance scheduling to extend the overall life cycle of the boiler. However, steam boilers are commonly plagued with issues such as boiler shutdown and tube leakage. Industry experts adopted preventative maintenance to overcome the repetition of outage in steam boilers. This method is flawed in the aspect of redundant maintenance activities. The repetition in maintenance activities will lead to reduced work productivity and increased maintenance operational costs. In this study, a maintenance optimization system specialized in ranking, prioritization and optimization based on Analytical Hierarchy Process (AHP) and Particle Swarm Optimization (PSO) are chosen. The AHP is used to rearrange the maintenance activities according to its priority while the PSO is an intelligent swarm used to optimize the operational duration and maintenance cost based on the result formed from AHP after implemented using MATLAB software. This work proposes maintenance scheduling based on minimization of the objectives focusing on the forming new list of the maintenance activities with the optimal operational duration and maintenance cost.
\end{abstract}

Index Terms: Steam boiler, maintenance optimization, analytical hierarchy process, particle swarm optimization.

\section{INTRODUCTION}

In Malaysia, there are two main types of power generating electricity from primary energy sources. There are thermal power plant and hydro power plant. Steam power plant generate power by firing coal, oil or natural gas using conventional steam turbine and steam generator. Coal heavily dominates the market as a fuel due to economic factors and movements to reduce dependency on natural gas. [1].

Thermal power plant is composed of steam boiler, steam turbine, furnace and chimney [2]. According to Damian Flynn and Constantine Samaras, steam boiler has the highest in major outage and maintenance cost as illustrated in Fig 1 $[3,4]$. Power plant boiler is the most complicated industrial component which involved the nonlinear, phase-change and inverse-response performance and plays as an important equipment in modelling and simulation challenge [5]. Boiler inadequacy and abrupt shut downs incur losses to annual revenues and harm other main components [6]. Therefore, each equipment must be maintained efficiently.

Revised Manuscript Received on August 18, 2019

Noor Fazreen Ahmad Fuzi, Power Generation Unit, Institute of Power Engineering (IPE), Universiti Tenaga Nasional (UNITEN), Kajang, Selangor, Malaysia.

Firas Basim Ismail, Power Generation Unit, Institute of Power Engineering (IPE), Universiti Tenaga Nasional (UNITEN), Kajang, Selangor, Malaysia.

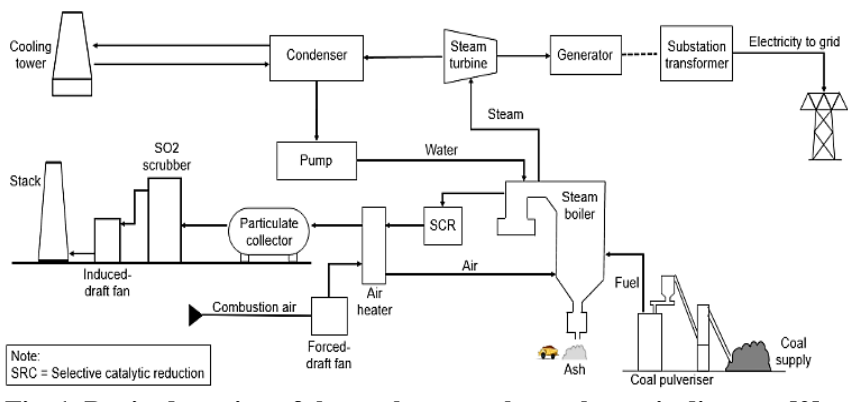

Fig. 1. Revised version of thermal power plant schematic diagram [2]

Maintenance strategy can be defined as maintenance technique that been used in an industry. There are three main maintenance strategies that used widely in an industry which are corrective maintenance, predictive maintenance and preventive maintenance. Preventive maintenance $(\mathrm{PM})$ is defined as a scheduling maintenance where the maintenance is scheduled to minimize breakdown or failure. PM is used widely which relate to age of the equipment. In order to build a PM system, it is important to prioritize machinery with high number of shutdown and repairs [7,8]. According to Shubham Agrawal, the most time-consuming maintenance activity is the overhaul. The overhauling process is the process comprises of cleaning, repairing and testing selected equipment. Every overhauling process need the system to be shut down for an estimated duration of 35 to 40 days [4].

Maintenance strategy selection is very important in industries nowadays. Based on Deryk Anderson, $80 \%$ of preventive maintenance cost are invested on the maintenance scheduling which running within 30 days and another $30 \%$ to $40 \%$ of the costs are invested on unnecessary breakdowns [9]. These are mainly down to inefficient maintenance process as redundant activities consume longer duration, or aging equipment [10]. Redundancy in maintenance activities is also one of the factors that affect the operation deterioration [11]. Ranking and prioritization process in maintenance activities is adopted in this work to solve the problem.

To make a decision in ranking and prioritization maintenance tasks, the Multi-Criteria Decision Making (MCDM) is adopted in this work. According to Jafar Rezai, a reviewer on MCDM found 152 publications on Analytical Hierarchy Process (AHP), fuzzy AHP, ANP, ELECTRE, TOPSIS, and more from 1990 to 2014. [12]. For this project, AHP which is developed by Saaty (1970) will be adopted as a method to redetermine the maintenance activities [13].

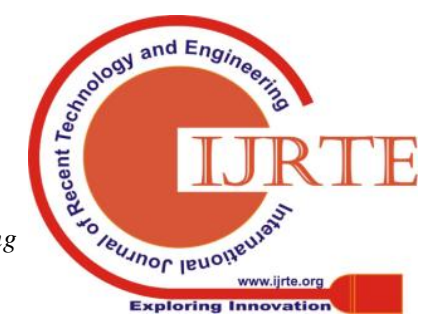


Other than that, maintenance optimization using swarm intelligence algorithm will be applied in this work to optimize operational time and cost. In these contemporary years due to the gradual development ideology, PSO are considered the most effective optimization tool due to its wide application in power engineering industry. PSO is a stochastic population-based optimization algorithm that was initiated by Kennedy and Eberhart (1995) [14,15]. PSO is an optimization method that gave more reliable result compare to other method. Furthermore, there are some researcher that already preferred PSO for power plant maintenance scheduling for example Ali Heidari (2014), Qiang Chou (2014), Giftson Samuel (2014), C.M.N.A Pereira (2009) and Raul Garduno-Ramirez (2005) [16-20]. This work will also further review on the implementation of AHP and PSO in maintenance optimization for thermal power plant.

The fundamental principle in this work is forming a new optimized list of maintenance scheduling. Based on the new list of maintenance activities, the operational time and cost will be minimized and the productivity of the worker is increased. The prioritization method is used to check and ensure reliability. The maintenance optimization model will produce reliable new maintenance activities with the shortest operational time. This will help the workers to reduce the redundancy of the activities that always occur in the preventive maintenance.

\section{RANKING AND PRIORITIZATION}

\section{A. Overview on Basic AHP}

Thomas Saaty (1980) initiated AHP approach as a competent method for a judgement team to decide the priorities and achieve the main objective to have better decision. The AHP approach is responsible to reduce a complex decision into a set of pairwise comparison to restructure the result and achieve the objective of the decision. This AHP approach also known as a group of evaluation basis and second option to decide the best decision. It is important to ensure that these criteria could be compare.

According to Saaty (1980), AHP is a flexible and effective method due to the scoring and final ranking based on pairwise relative evaluation of both criteria and the option provided by the judgement team. The computation of AHP is made by the judgement team's knowledge which is defined in this work as expertise in a company or organization.AHP also works as an approach to interpret the results either qualitative or quantitative into a multicriteria ranking. This ranking and prioritization method are the simplest and user-friendly user because it is based on expertise knowledge to implement it.

Furthermore, the AHP approach can be adopted into a group of evaluations including problems with a large number of criteria and options. Even though the method is simple, the result might come out unreasonable due to the validation made by the expertise involved. The matrices made must be quadratically with the number of criteria and options. However, to minimized the expertise's duty, the AHP can be partially or completely computed by adjusting the initial step of the pairwise comparisons.

\section{B. Decision Criteria in AHP}

AHP will examine a group of evaluation criteria and alternative options, then deciding the best outcome. The AHP evaluates each criterion by generating weight according to the decision-making team's pairwise comparisons.

Firstly, to set the objective in maintenance optimization, a generic list of maintenance optimization criteria can be used as reference. Based on expertise in a company, a prioritization among those criteria should be made. In the Fig 2 is the example of generic list

\begin{tabular}{|ll|}
\hline Maintenance cost & Availability \\
Maintenance quality & Reliability \\
Personnel management & Maintability \\
Inventory of spare parts & Environmental impact \\
Overall equipment effectiveness & Safety/risk \\
Number of maintenance interventions & Logistics \\
Capital replacement decisions & Output quantity \\
Life-cycle optimization & Output quality \\
\hline
\end{tabular}

Fig. 2. General list of optimization [22]

Next, computing the vector of the criteria weights. The AHP starts creating a pairwise comparison matrix $\mathrm{P}$. The matrix $\mathrm{P}$ is $\mathrm{a} \mathrm{b} \mathrm{x} \mathrm{c} \mathrm{real} \mathrm{matrix} \mathrm{where} \mathrm{b}$ is the number of evaluation criteria considered.

$$
P=\left[\begin{array}{ccc}
1 & \cdots & n \\
\vdots & \ddots & \vdots \\
1 / n & \cdots & 1
\end{array}\right]
$$

After that, computing matrix option score. The $\mathrm{b} x \mathrm{c}$ real matrix $\mathrm{P}$ is known as the matrix of option scores. The score matrix $\mathrm{P}$ is obtained as follow:

$$
P=\left[\begin{array}{lll}
p^{1} & \cdots & p^{n}
\end{array}\right]
$$

To know the reliability of the matrix form, the consistency must be check. The check the consistency, below is the three steps that need to be follows:

The $\lambda_{\max }$ is the highest eigenvalue of the matrix has to be calculated,

$$
\lambda=\frac{\sum[\text { Consis }]}{n}
$$

The consistency index (CI) is calculated as follow,

$$
C I=\frac{(\lambda-\mathrm{n})}{(\mathrm{n}-1)}
$$

The matrix is perfectly consistent when $C I=0$.

The number of pair wise comparisons increases with respect to the possibility of consistency error. Thus Saaty (1980) introduced another method to calculate the CR (Consistency Ratio),

$$
C R=\frac{C I}{R I}
$$

Where RI is random consistency as shown in table below,

TABLE I. 
AVERAGE RANDOM CONSISTENCY (RI)

\begin{tabular}{|c|c|c|c|c|c|c|c|c|c|}
\hline$m$ & 2 & 3 & 4 & 5 & 6 & 7 & 8 & 9 & 10 \\
\hline$R I$ & 0 & 0.58 & 0.90 & 1.12 & 1.24 & 1.32 & 1.41 & 1.45 & 1.51 \\
\hline
\end{tabular}

The Consistency Ratio (CR) is used to ensure that the AHP matrices form is reliable. This is because this AHP is based on expertise decision maker, so the $\mathrm{CR}$ is required to prove the reliability. If the $\mathrm{CR}$ value is below than 0.10 , the matrices form is reliable. However, if the value is equal or higher than 0.10 , the matrices form is not reliable recalculation is needed. Lastly, the options are ranked based on the CR value obtained accordingly. The weight vector, $w$ and the score matrix $\mathrm{S}$ computed, the AHP obtains a vector $v$ of global scores by multiplying A and $w$ as in eq. (4). Lastly, the option is ranked according to the global scores in increasing order.

$$
v=A \times w
$$

To be concluded, all the ranking and prioritization step are based on previous studies and the model of the AHP can be made in the Microsoft Excel. Most of the Multi Criteria Decision Making (MCDM) methods are easy to implement. In this work, AHP is chosen is due to its capability of meeting inconsistent objectives. Most of the previous work use AHP to study the judgement on expenses, operability, reliability and flexibility, and also machine ability where most of them proved the result in logical consequence. Besides, the AHP is able to detect the inconsistent judgement based on consistency ratio (CR) [21-29]. Therefore, AHP is selected.

\section{INTELLIGENCE MAINTENANCE OPTIMIZATION STRATEGIES}

\section{A. Maintenance Optimization in Thermal Power Plant}

Maintenance optimization is beneficial in building a competent maintenance program to determine plant dependability based on safety and cost [30]. Optimizing preventive maintenance of thermal power plant usually focuses on operational time and cost [31]. There are a lot of optimization method that been used by the researcher. As for Maria Carmen, she did implement MACBETH and Markov chain as her maintenance optimization model to optimize preventive maintenance in electric power distribution systems [32]. For Loganathan, he used the risk-based maintenance (RBM) to optimize unexpected failure and down time in any power-generating plant [33] and as for Andrija Volkanovski, he implemented heuristic algorithm to optimize maintenance activities in nuclear power plant [34].

Nowadays the most reliable and effective optimization method are Stochastic-based algorithm (Simulated Annealing), Evolutionary Algorithm (Genetic Algorithm, GA) and Swarm-based optimization algorithm (PSO and Ant Colony Optimization, ACO) [10]. Simulated Annealing (SA) was introduced by Kirkpatrick, where it often implemented in independent search spaces. However, it is incompatible to be applied for optimization problem if the variables are continuous [35].

According to Fraser who developed studies on inheritance of GA found out that GA is the combination of function evaluation with the randomized and exchanged information among the solutions in order to achieve the global optimal
[36]. ACO is one of the ant colony algorithm group in the swarm intelligence approaches and was initiated by Marco Dorigo. It is suitable to be applied in finding the optimal path where only various number of search space is involving. Therefore, it can be concluded that ACO is not suitable to be applied in optimization problem which continuous variables [37].

Lastly, PSO is an algorithm motivated by social behavior of a group of bird, initiated by Dr Eberhart and Dr Kennedy. The particles develop in the search space with stated position and velocities where the position of the particle with terrific fitness value is served by the other particles based on the adjustment of the velocities [38]. According to M. Clerc, PSO is applicable for optimization problem with continuous variables and faster in generating result compared to other global optimization methods [39]. This work will focus on PSO to determine the maintenance optimization problem.

\section{B. PSO Ideologies}

PSO and GA are the most similar in the system where started with the population of random velocity and the potential solution known as particle. To compare with GA, PSO had the randomized space. PSO is a clarification for optimization based on simulation of a rationalize common behaviour. In PSO, a flock arrangement conceals the choice of solution which known is as particles, will "fly" in the n-dimensional search space of the optimization problem to determine the climax or near-climax domains. There are two components that will be used as a guidance to conduct PSO which are the subjective report according to particles' involvement and the common knowledge based on neighbour's review.

In the last few years, PSO has been adopted in research and operation areas. It has been proven that PSO is more efficient compared to the other optimization methods. Besides that, parameters in PSO are able to be adjusted based on the problem. First, the minor variations performed better in a wide array of applications. Particle swarm optimization had been implemented to approach the wide scope of applications for approaches for definite applications with the specific necessity.

In addition, to identify the best solution termed as fitness, each particle will keep on track of its coordinates in the problem space. Then, fitness value is stored, known as pbest. Another best value in PSO is the gbest. Gbest is the overall best value where it is tracked by the global version in the particle swarm optimizer and its location is determined by any of the particle in the population. The PSO concept consists of, changes in the velocity of each particle or known as accelerating against its pbest and gbest locations, global version of PSO, at each stated time. Acceleration is defined as the random duration weighted with respective random numbers developed for acceleration toward pbest and gbest locations. Let,

$$
\begin{aligned}
v_{i, n}(t+1)= & w * v_{i, n}(t)+c_{1} r_{1} \text { Pbest }_{i, n}(t)-x_{i, n}(t) \\
& +c_{2} r_{2}\left(\text { Gbest }_{i, n}(t)-x_{i, n}(t)\right. \\
& \sum_{i}^{n} x(t+1)=\sum_{i}^{n} x(t)+v(t+1)
\end{aligned}
$$


Where the position $x$ and the velocity $v$ of the particle $i$ in stated time $t$, in a n-dimensional search space.

Considering that,

$$
P_{\text {best }}(t)=\sum_{i}^{n} P_{\text {best }}(t)
$$

Where particle $i$ is the best position found until time $t$ and

$$
G_{\text {best }}(t)=\sum_{i}^{n} G_{\text {best }}(t)
$$

Where the random numbers $\left(r_{1}\right.$ and $\left.r_{2}\right)$ between zero and one, and the coefficient $\left(c_{1}\right.$ and $\left.c_{2}\right)$ where the acceleration is constant towards Pbest and Gbest accordingly and $\mathrm{w}$ is the inertia weight, to identify the scope of the study in the search space. The high value of $\mathrm{w}$ developed in the global search while the low value will lead to a local search. Therefore, a common approach is needed to ensure the balance between the global and local search decreasing linearly in the search process. Next, the swarm is randomly initialized. If the stopping criterion is not achieved, the particles will move based on the velocity and positions equation as shown in Fig. 2 and eq. (5) - (8) [40-51].

PSO is chosen in this work. This is because compare other optimization method such as Genetic Algorithm and Heuristic method, PSO has the shortest time taken per run. Other than that, PSO is easier to implement especially in terms of cost optimization because PSO only required minimum number of algorithm parameters. Lastly, PSO has its own swarming effect where it changes individually based on the global optimal point. This swarming effect is only found in PSO [43].

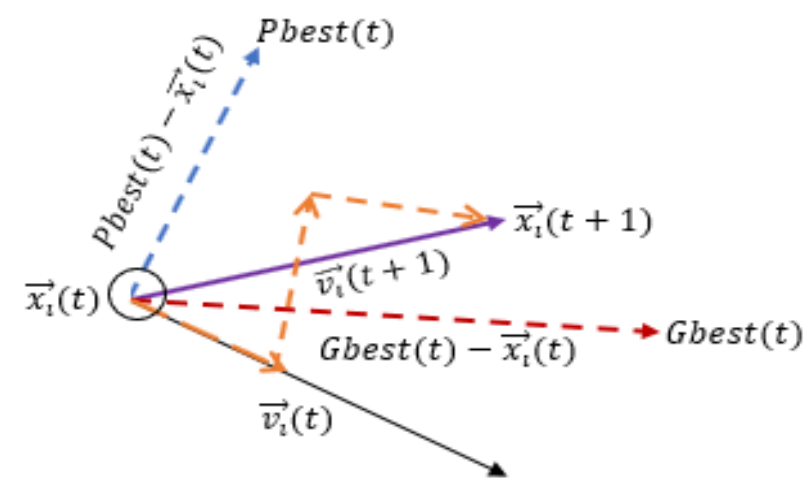

Fig. 3. Basic concept of searching point in PSO

\section{CONCLUSION}

To conclude, a review of existing maintenance optimization schedules is analyzed and a new optimized version of preventive maintenance activity scheduling is introduced in this work. Effective and reliable maintenance scheduling should be implemented worldwide in this industry to manage the equipment more efficiently in terms of operational duration and cost. The preventive maintenance for steam boiler thermal power plant had been studied and evaluated. The analysis singles out boiler overhaul as the most preferable due to its high ranking in operational duration and maintenance cost. The prioritization of the maintenance activities using AHP is implemented and new reliable maintenance activities is formed. Lastly, PSO is adopted to achieve the main purpose of the work.

\section{ACKNOWLEDGMENT}

Authors would like to express gratitude to Power Generation Unit, Institute of Power Engineering (IPE), University Tenaga Nasional (UNITEN) and Tenaga Nasional Berhad (TNB) for providing research grant to carry out this research.

\section{REFERENCES}

1. Tenaga Nasional Berhad (TNB) website. [Online]. Available: https://www.tnb.com.my/about-tnb/our-business/\# [accessed September 2018]

2. H.Kubota, "Case tudy: the Manjung $4 \& 5$ coal fired power stations in Malaysia - similiarities and differences," 1-31, June 2015.

3. D. Flynn, Thermal power plant simulation and control. The Institution of Electrical Engineers.

4. A. Chandra, M. William, K. Ricci, "Characterizing the U.S industrial base for coal-powered electricity," RAND Corp., 60-73, 2011.

5. P. Sunil, J.Barve, P. Nataraj, "Boiler model and simulation for control design and validation". IFAC proceeding, vol 3, Part 1, 2014, pp 936-940.

6. N. Zhakiyev, Y.Akhmetbekov, J.Silvente, Kopanos G, “Optimal energy dispatch and maintenance of an industrial thermal combined heat and power plant in Kazakhstan". Energy Procedia, vol 142, 2017, pp 2485-2490.

7. A.Borikar, A.Shingare, J.Sarnaik, A.Bhusari, "Implementation of total productive maintenance on boiler". ICAET, 2014, pp34-38.

8. M.Dachyar, R.Nurcahyo, Y.Tohir, "Maintenance strategy selection for steam power plant in range of capacity $300-625 \mathrm{MW}$ in Indonesia". ARPN J. of Engineering and Applied Sciences, 13, 2018, 2571-2580.

9. Accenture. "Reducing the cost of preventive maintenance," 15-3169_lc, 2015

10. H.Ge, "Maintenance optimization for substation aging equipment," Electrical Engineering Theses and Dissertation, 2010, pp 7.

11. W.Wang. Z.Wu. J.Xiong. Y.Xu. "Redundancy optimization of cold-standby systems under periodic inspection and maintenance" Reliability Engineering and System Safety, vol 180, 2018, pp 394-402.

12. J.Rezaei. "A systematic review of multi-criteria-decision-making applications in reverse logistics" Transportation Research Procedia, vol 10, 2015, pp 766-776.

13. T.Saaty, The Analytic Hierarchy Process. McGraw-Hill, New York, 1980

14. R.H.Ramadhan, H.I.A.Wahhab, S.O.Duffuaa, "The use of an analytical hierarchy process in pavement maintenance priority ranking", J. of Quality in Maintenance Eng., Vol. 5 Iss: 1, 1999, pp. 25 - 39.

15. N.Yusof, S.Salleh, "Analytical hierarchy process in multiple decisions making for higher education in Malaysia". Procedia-Social and Behavioral Sciences 81, 2013, 389-394.

16. A.Heidari, "Using the PSO algorithm for power plants maintenance scheduling in the restructured network". Indian J Sci Res 2(1):76-80, 2014.

17. Q.Chou, D.Ge, R.Zhang, "PSO based optimization of testing and maintenance cost in NPPs," Science and Technology of Nuclear Installations, 1-9, 2014.

18. G.G.Samuel, C.C.A.Rajan, "Hybrid: particle swarm optimization-genetic algorithm and particle swarm optimization shuffled frog leaping algorithm for long term generator maintenance scheduling". Int. J. of Elect. Power and Energy Systems. Vol 65. pp 432-442., 2015.

19. C.M.N.A.Pereira, C.M.F.Lapa, A.C.A.Mol, A.F.da Luz, "A pso approach for preventive maintenance scheduling optimization". INAC, ISBN: 978-85-99141-03-8, 2009.

20. J.S.Heo, K.Lee, R.Garduno-Ramirez. "Multiobjective optimal power plant operation using particleswarm optimization technique". IFAC Proceeding, vol 38 (1), pp 363-368, 2005.

21. F.B.Ismail, "Design and implementation of intelligent monitoring systems for thermal power plant boiler trips". Thesis for Doctor of Philosophy (PhD). Dept. of Mechanical Engineering, Faculty of Engineering, University of Petronas, Malaysia, 2010.

22. A.V.Horenbeek, L.Pintelon, P.Muchiri, "Maintenance optimization models and criteria,'Int J Syst Assur Eng Manag, 1(3):189-200, 2010.

23. J.Franek, A.Kresta, "Judgement scale and consistency measure in ahp". Procedia Economics and Finance 12, pp 164-173, March 2014. 
24. K.M.A.Al-Harbi, "Application of the ahp in project management," International Journal of Project Management 19-27, 2001.

25. R.Russ, R.Camanho, "Criteria in AHP: a systematic review of literature," Procedia Computer Science, vol 55, pp 1123-1132, 2014.

26. G. Coyle, The Analytical Hierarchy Process (AHP). 2004.

27. A.Ishizaka, A.Labib, "Review of the main developments in the analytic hierarchy process". Expert Systems with Applications, vol 38 (11), pp 14336-14345, 2011.

28. T. Ganesh, P.Reddy, "Testing the consistency of subjective weight in goal programming - the analytical hierarchy process approach". American J. of Applied Matehmatics and Sciences, vol 2 (3), pp 92-95, 2014.

29. R.Perzina, J.Ramik, "Microsoft Excel as a tool for solving multicriteria decision problems". Procedia Computer Science, vol 35, C, pp 1455-1463, 2014.

30. International Atomic Energy Agency. "Maintenance optimization programme for nuclear power plant". IAEAL 18-01147 | ISBN 978-92-0-110916-3, 2018.

31. O.Obodeh, P.E.Ugwuoke, "Optimal maintenance scheduling of thermal power units in a restructured nigerian power system," Journal of Mechanical Engineering Research, vol 5(8), 2013, pp 145-153.

32. M.Carnero, A.Gomes, "Maintenance strategy selection in electric power distribution systems," Energy 129, 2017, pp 255-272.

33. L.Krishnasamy, F.Khan, M.Haddara, "Development of a risk-based maintenance (RBM) strategy for a power-generating plant," J. of Loss Prevention in the Process Industries 18, 69-81, 2005.

34. A.Volkanovski, L.Cizelj, "Nuclear power plant maintenance optimization with heuristic algorithm," Sc and Tech of Nuclear Installation, 13 pages, 2014.

35. S.Kirkpatrik. C.D Gellat. M.P. Vecchi. "Optimization by simulated annealing," Science, vol 220, pp 671-680, 1983.

36. A.Fraser. "Simulation of genetic systems by automatic digital computers. I. Introduction". Aust. J. Biol. Sci. 10:484-491, 1957.

37. M.Dorigo, C.Blum, "Ant colony optimization theory:a survey", Theoretical Computer Science, 344, 243-278, 2005.

38. R.C Eberhart. J.A. Kennedy. "A new optimizer using particle swarm theory," [Sixth Int Symp on M.machine and Human Sci, 39-43, 1995.

39. M.Clerc. "Particle swarm optimization", ISTE, 2006.

40. V.Rane. "Particle Swarm Optimization (PSO) Algortihm: Paramters Effect and Analysis". Vol 2, Issue 7, pp 8-16, 2013.

41. K.Suresh. N.Kumarrapan. "Particle Swarm Optimization based on generation maintenance scheduling using probabilistic approach". Procedia Engineering 30, 2012, 1146-1156.

42. M.Bonyadi, "Particle Swarm Optimization: Theoretical analysis, modifications and applications to constrained optimization problems". Thesis for Doctor of Philosophy (PhD). School of Computer Science. Faculty of Engineering, Computer, and Mathematical Sciences. The University of Adelaide, 2014.

43. C.A.Koay, D.Srinivasan, "Particle swarm optimization-based approach for generator maintenance scheduling," Int.Conf. Swarm Intell Symp, 1, 2003, pp 167-173.

44. N.Kulkarni, S.Patekar, T.Bhoskar, T.Omkar, G.M. Kakandikar, V.M Nandedkar, "Particle swarm optimization applications to mechanical engineering-a review". [Mat. Today, vol 2, 4-5, 2015, pp 2631-2639]

45. O.Ertelince, C.Kalayci, "A survey of swarm intelligence for portfolio optimization: algorithms and applications," Swarm and Evolutionary Computation, vol 39, 2018, pp 36-52.

46. S.Carlos, A.Sanchez, S.Martorell, J.F. Villanueva, "Particle swarm optimization of safety components and systems of nuclear power plants under uncertain maintenance planning". Advances in Engineering Software, vol 50, 1, 2012, pp 12-18.

47. J.Wang, Z.Zhai, Y.Jing, C.Zhang, "Particle swarm optimization for redundant building cooling heating and power system," Applied Energy, vol 87, 12, 2010, pp 3668-3679.

48. Q.Chen, X.Yang, G.He, X.Zhou, "Optimal scheduling system for wind farm and hydro power plant coorindating operation," Energy Procedia, vol 145, 2018 pp 277-282.

49. C.Wang, T.Lin, "Improved particle swarm optimization to minimize periodic preventive maintenance cost for series-parallel systems". Expert Systems with Applications, vol 38, 7, 2011, pp 8963-8969.

50. A.Piotrowski, M.Napiorkowski, J.Napiorkowski, M.Rowinski, "Swarm intelligence and evolutionary algorithm: performance versus speed". Information Sciences, vol 384, 2017, pp 34-85.

51. T.Sundaram. F.B.Ismail. P.Gurusingam. "Soot blowing operation optimization using PSO methos by studying behaviour of operating parameter in sub critical coal fired power plant". MATEC Web of Conf, 225, 01005, 2018.

52. J.Schutte. "The particle swarm optimization algortihm". EGM 6365 Structural Optimization Fall, 2005.

\section{AUTHORS PROFILE}

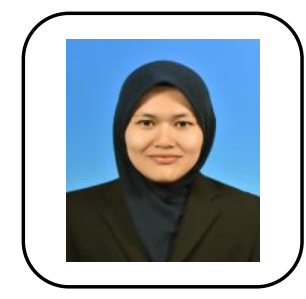

Noor Fazreen Ahmad Fuzi, working as research engineer under Power Generation Unit, Institute of Power Engineering, UNITEN. She is currently pursuing Master in Mechanical Engineering in UNITEN. Her research interests are focused in power generation and optimization techniques. She has published 2 publications in SCOPUS Indexed journals and conference proceedings.

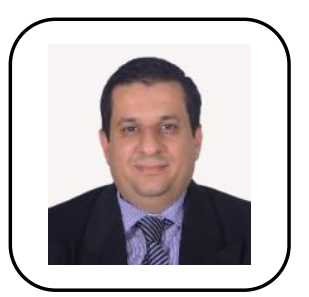

Dr Firas B. Ismail Alnaimi is a Head of Power Generation, Institute of Power Engineering (IPE), UNITEN, Malaysia. He has 13 years working experience in industry and academic fields. His research focus is on Intelligent Monitoring Systems, with special interests in Fire, Flow Assurance, Smart Pigging Systems, Gas Hydrate Formation, Early Condition Warning Systems, Plant Monitoring Systems, and Robotized Industry Applications. He has published more than 90 publications in reputable international journals and conference proceedings. 